DE GRUYTER GOSPODARKA SUROWCAMI MINERALNYMI - MINERAL RESOURCES MANAGEMENT

\title{
Cząstki węglowe w popiołach lotnych ze spalania węgla z polskich złóż
}

\section{Wprowadzenie}

Podczas spalania węgla substancja mineralna w nim zawarta pozostaje jako odpad w formie żużla paleniskowego i popiołu lotnego. W popiołach lotnych ulega ona częściowemu upłynnieniu, równocześnie podlega skomplikowanym przemianom fizykochemicznym polegającym na dehydroksylacji uwodnionych glinokrzemianów i krzemianów glinu, częściowej mullityzacji, rozkładu węglanów, redukcji tlenków żelaza i rozpadu siarczków żelaza (Jonczy i in. 2012). Szybkie schłodzenie produktów spalania sprzyja tworzeniu się amorficznych (niekrystalicznych) cząstek często o kształcie kulistym - mikrosfery, a uwięzione w nich gazy rozszerzając się mogą tworzyć cenosfery. Minerały o wysokiej temperaturze topnienia mogą pozostać względnie niezmienione (Kutchko i Kim 2006). Popioły lotne zawierają w swoim składzie również nie do końca spaloną substancję organiczną w formie ziaren lub cenosfer.

Wiedza na temat właściwości fizykochemicznych, składu chemicznego i składu mineralnego popiołów lotnych pozwala na określenie sposobu utylizacji lub możliwości ich wykorzystania. Od kilkudziesięciu lat są one stosowane jako główny składnik cementu i dodatek do betonu (Giergiczny 2013). Stosowane są również jako materiał podsadzkowy w górnictwie (Mazurkiewicz i in. 1997) Możliwe jest również wykorzystanie popiołów lotnych w przemyśle chemicznym, ceramicznym oraz rolnictwie (Bech i Feuerborn 2008). Mogą być one również stosowane do wiązania $\mathrm{CO}_{2}$ na drodze mineralnej karbonatyzacji (Uliasz-Bocheńczyk 2008).

* Dr inż., AGH Akademia Górniczo-Hutnicza, Wydział Geologii Geofizyki i Ochrony Środowiska, Katedra Geologii Złożowej i Górniczej, Kraków; e-mail: misiak@agh.edu.pl 


\section{Mikrocząstki popiołów lotnych i ich klasyfikacja}

W literaturze można spotkać wiele klasyfikacji mikrocząstek popiołu lotnego ze względu na skład chemiczny i fazowy. Przykładowo Fisher (1978) zidentyfikował 11 typów mikrocząstek popiołu lotnego z zastosowaniem mikroskopii optycznej. Ramsden i Shibaoka (1982) wyróżnili siedem typów mikrocząstek za pomocą mikroskopu skaningowego. Z kolei Jun-Min i inni (2001) zaproponowali wydzielenie pięciu grup składników w popiołach lotnych. Skład popiołów może się zmieniać w zależności od pochodzenia węgla, sposobu spalania (rodzaju kotła). Ziarna przyjmują różne formy mikromorfologiczne zróżnicowane zarówno pod względem kształtu jak i porowatości (Ratajczak i in. 1999). Głównym składnikiem popiołów (Shackelford i Doremus 2008) jest szkliwo (szkło) krzemionkowo-glinowo -potasowe. Fazami krystalicznymi są: kwarc, mulit, hematyt, magnetyt (Kurdowski 2010).

Tlenki żelaza tworzą się w wyniku utleniania siarczków żelaza (pirytu, markasytu) zawartych w węglu. Ich ilość w produktach spalania nie przekracza $\mathrm{z}$ reguły kilku procent. Najczęstszą formą jest magnetyt, który tworzy na ogół formy kuliste o strukturze dendrytyczno-szkieletowej, często spojone substancją glinokrzemianową (Sokół i in. 2002).

Związki wapnia to głównie gips i anhydryt występujący najczęściej w formie konglomeratów lub ziaren (Jonczy $i$ in. 2012).

Niespalona materia organiczna w popiołach lotnych występuje najczęściej w formie ziaren masywnych lub porowatych, często przyjmujących postać cenosfer. Propozycja szczegółowej klasyfikacja tych cząstek opracowana została przez ICCP - International Committee for Coal and Organic Petrology (Lester i in. 2010). Wydzielono następujące typy cząstek węglowych:

- Tenuisphere - formy kuliste lub zbliżone do wielokąta o porowatości od 80 do 50\% i grubości ścianek poniżej $3 \mu \mathrm{m}$.

- Crassisphere - formy kuliste lub zbliżone do wielokąta o porowatości od 60 do 50\% i grubości ścianek powyżej $3 \mu \mathrm{m}$.

- Tenuinetwork - formy nieregularne o porowatości od 70 do 50\% i grubości ścianek poniżej $3 \mu \mathrm{m}$.

- Crassinetwork - formy nieregularne o porowatości od 40 do 50\% i grubości ścianek powyżej $3 \mu \mathrm{m}$.

- Mixed Porous - cząstki częściowo upłynnione o porowatości powyżej 60 \%, zawierające do $25 \%$ materiału nieprzetopionego.

- Mixed Dence - cząstki częściowo upłynnione o porowatości od 40 do 60 \%, zawierające do $75 \%$ materiału nieprzetopionego.

- Inertoid - zwarty o porowatości 5-40\%.

- Fusinoid/Solid - cząstki o zachowanej strukturze fuzynitu lub cząstki lite o porowatości poniżej 5\%.

- Mineroid - cząstki zawierające powyżej 50\% substancji nieorganicznej. 


\section{Materiały i metodyka badań}

Próbki popiołów lotnych do badań (o kodzie 100102 według katalogu odpadów), pochodzą z elektrociepłowni opalanych węglem brunatnym i kamiennym spalanym w kotłach pyłowych.

Preparaty do badań wykonano w formie brykietów polerowanych standardowo, stosowanych do badań mikroskopowych w świetle odbitym w immersji.

Badania petrograficzne wykonano przy użyciu mikroskopu optycznego, polaryzacyjnego Axioskop firmy Opton przystosowanego do obserwacji w świetle odbitym oraz we fluorescencji. Do obserwacji użyto obiektywu immersyjnego o powiększeniu 50 razy. Analiza ilościowa została wykonana metodą punktową za pomocą integratora Eltinor.

W celach dokumentacyjnych oraz do określenia porowatości wykonano zdjęcia mikroskopowe obserwowanych cząstek węglowych. Porowatość określono stosując komputerową analizę obrazu poprzez binaryzację i progowanie odcieni szarości (Tadeusiewicz i Korhoroda 1997; Alvarez 1997).

\section{Wyniki badań}

W badanych popiołach lotnych ze spalania węgli brunatnych pochodzących z elektrowni Bełchatów stwierdzono występowanie mikrocząstek należących do następujących grup: glinokrzemiany (kwarc, mulit), tlenki żelaza, węglany oraz niespalona substancja organiczna. Substancja organiczna $\mathrm{w}$ badanych próbkach z elektrociepłowni Bełchatów występuje w ilości 6,2\% (tab. 1).

Tabela 1. Zawartość niespalonego węgla w badanych popiołów lotnych (vol. \%)

Table 1. The content of unburnt coal in the fly ash (percentage volume)

\begin{tabular}{|c|c|c|c|c|c|c|c|c|c|c|c|}
\hline $\begin{array}{l}\mathrm{Nr} \\
\text { pr. }\end{array}$ & Elektrociepłownia & Paliwo & $\begin{array}{c}\text { Zawartość } \\
\text { cząstek } \\
\text { organicznych } \\
{[\%]}\end{array}$ & Detritus & $\begin{array}{l}\text { Tenui- } \\
\text { sphere }\end{array}$ & $\begin{array}{l}\text { Crassi- } \\
\text { sphere }\end{array}$ & $\begin{array}{l}\text { Tenui- } \\
\text { network }\end{array}$ & $\begin{array}{l}\text { Crassi- } \\
\text { network }\end{array}$ & Mixed & Inertoid & Solid \\
\hline 1 & Bełchatów & $\mathrm{wb}$ & 6,2 & 2,6 & 0,1 & 0,2 & 0,1 & 1,2 & 1,1 & 0,8 & 0,1 \\
\hline 2 & Dolna Odra & wk & 7,9 & 3,3 & 0,1 & 0,7 & 0,1 & 1,8 & 1,2 & 0,5 & 0,2 \\
\hline 3 & Janikowo & wk & 7,2 & 2,2 & 0,1 & 0,8 & 0,2 & 2,1 & 1,1 & 0,6 & 0,1 \\
\hline 4 & Jaworzno & wk & 4,8 & 1,2 & 0,2 & 0,5 & 0,2 & 0,5 & 1,3 & 0,8 & 0,1 \\
\hline 5 & Kozienice & wk & 6,5 & 1,7 & 0,1 & 0,7 & 0,1 & 0,8 & 2,4 & 0,4 & 0,3 \\
\hline 6 & Opole & wk & 6,5 & 1,9 & 0,3 & 0,5 & 0,1 & 0,9 & 2,1 & 0,5 & 0,2 \\
\hline 7 & Poznań & wk & 5,7 & 2,4 & 0,1 & 0,6 & 0,2 & 0,7 & 1,2 & 0,4 & 0,1 \\
\hline 8 & Siersza & wk & 4,1 & 1,4 & 0,1 & 0,3 & 0,1 & 0,4 & 1,3 & 0,3 & 0,2 \\
\hline 9 & Skawina & wk & 6,9 & 2,5 & 0,2 & 0,6 & 0,3 & 1,1 & 1,1 & 0,9 & 0,2 \\
\hline
\end{tabular}

wb - węgiel brunatny; wk - węgiel kamienny 


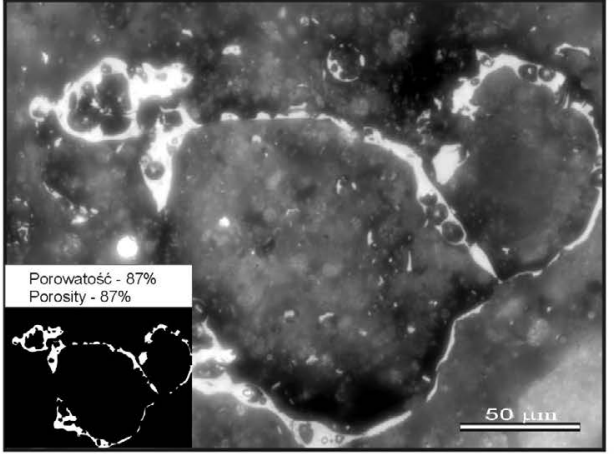

Fot. 1

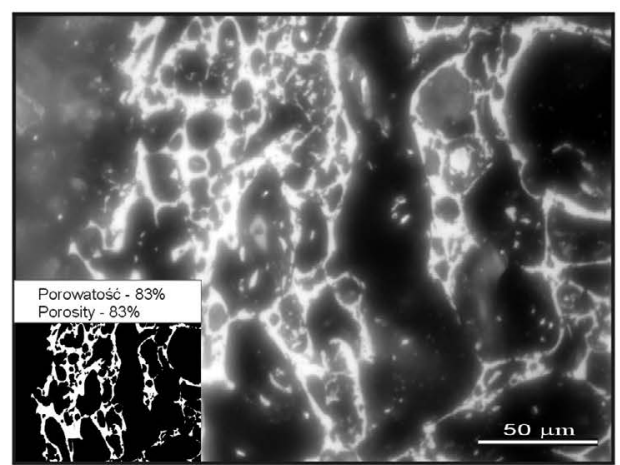

Fot. 3

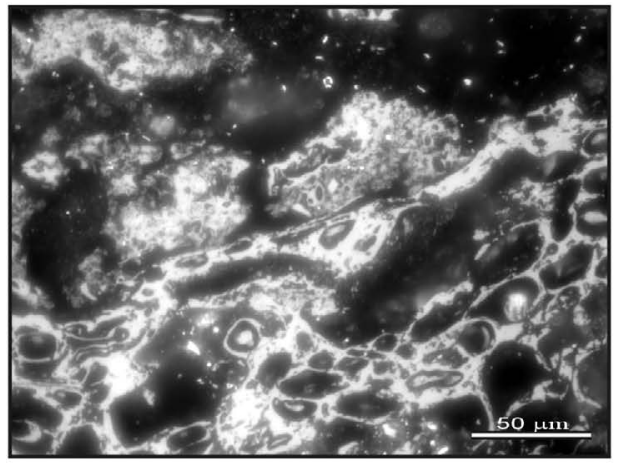

Fot. 5

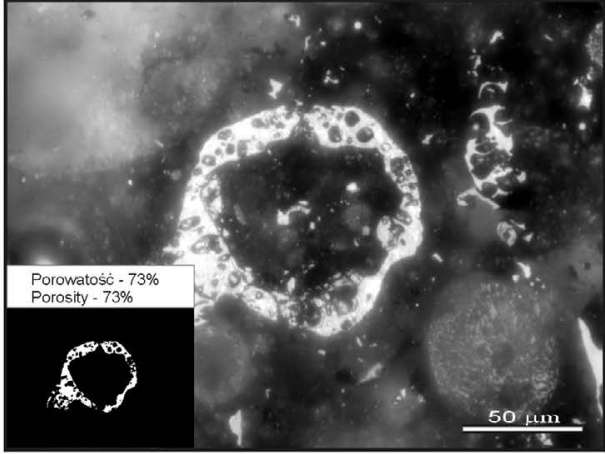

Fot. 2

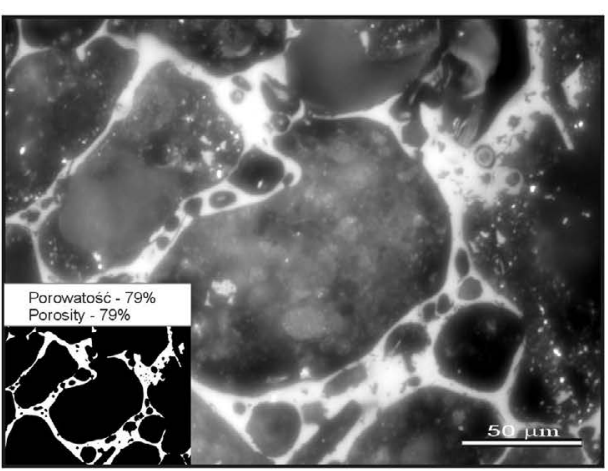

Fot. 4

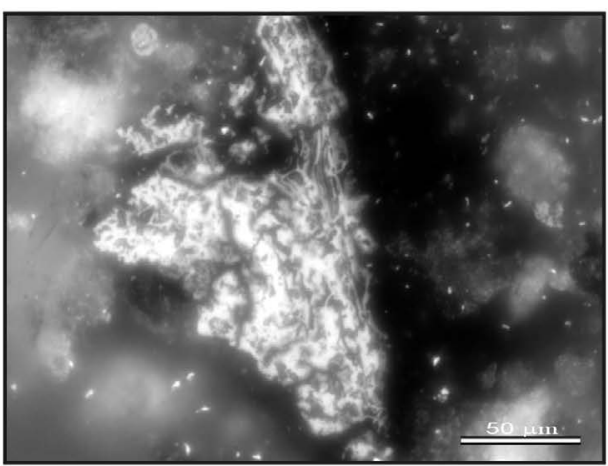

Fot. 6

Rys. 1. Formy sferyczne, porowate tenuisphere (fot. 1), crassisphere (fot. 2). Ziarna porowate tenuinetwork (fot. 3), crassinetwork (fot. 4)

Ziarna o złożonej budowie mixed porous (fot. 5), mixed dence (fot. 6)

Fig. 1. Spherical forms, porous tenuisphere (picture 1), crassisphere (picture 2), tenuinetwork porous grains (picture 3), crassinetwork (picture 4), grains of complex structure: mixed porous (picture 5), mixed dense (picture 6) 


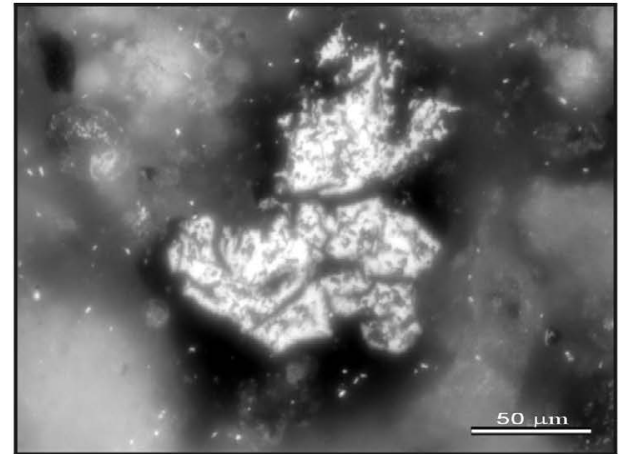

Fot. 7

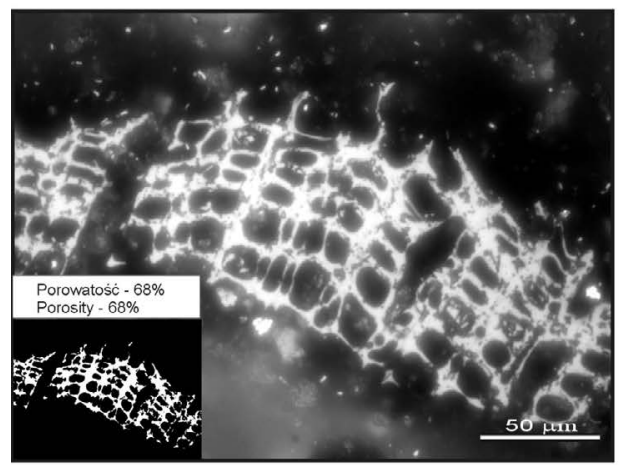

Fot. 9

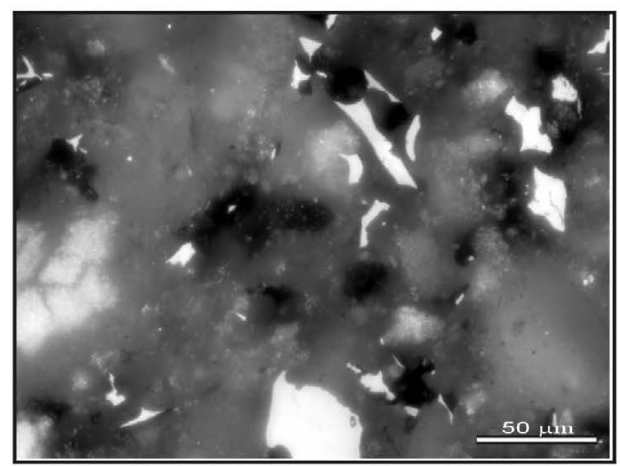

Fot. 11

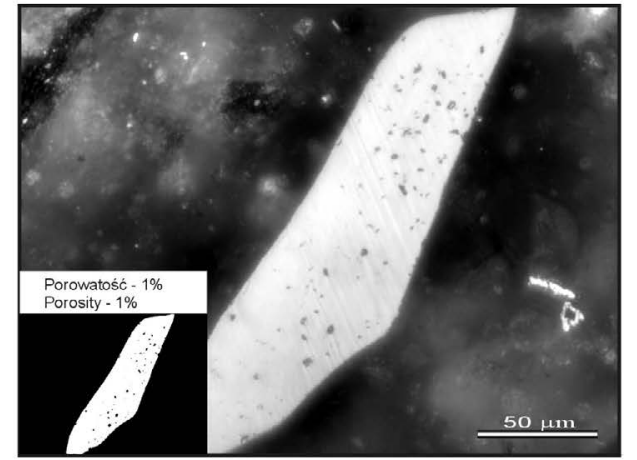

Fot. 8

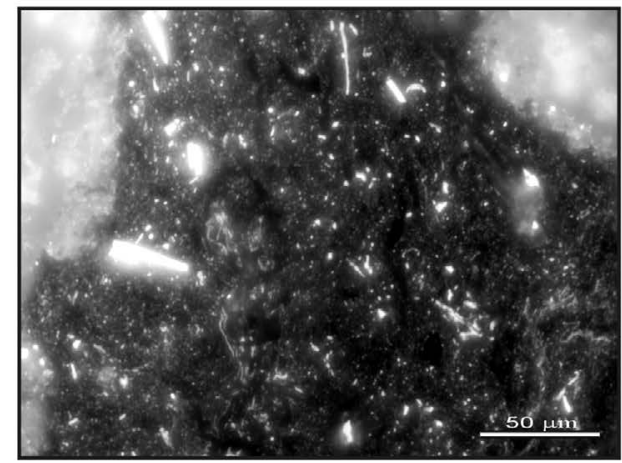

Fot. 10

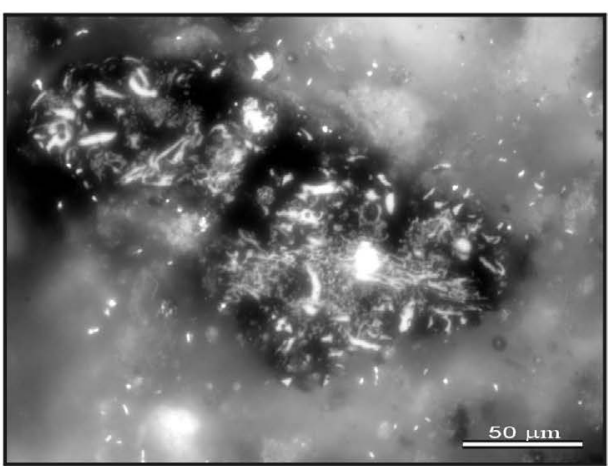

Fot. 12

Rys. 2. Formy zwarte (fot. 7), masywne (fot. 8). Fuzynit o dobrze zachowanej strukturze komórkowej (fot. 9). Ilość substancji mineralnej przekracza 50\%, (fot. 10)-mineroid. Substancja organiczna w formie detrytycznej (fot. 11),

zawierająca domieszki mineralne przeobrażonej substancji ilastej (fot. 12)

Fig. 2. Dense forms (picture 7), massive forms (picture 8), Fusinite showing cellular structure (picture 9). The mineral matter content exceeds $50 \%$, (picture 10 ) - mineroid.

Carbonaceous substance in the detrital form (picture 11), detrital form containing mineral admixtures of the transformed clay matter (picture 12) 
W popiołach lotnych ze spalania węgli kamiennych pochodzących z elektrowni Skawina, Siersza, Kozienice, Jaworzno, Janikowo, Poznań, Opole, Dolna Odra, stwierdzono występowanie mikrocząstek mineralnych analogicznych do wymienionych w opisie węgli brunatnych oraz cząstek niespalonego węgla w ilości od 4,1-7,9\% (tab. 1).

Cząstki organiczne wykazują duże zróżnicowanie zarówno pod względem wielkości jak i morfologii. Ich wielkość waha się w przedziale od kilku $\mu \mathrm{m}$ do około $1 \mathrm{~mm}$. Zgodnie z proponowaną przez ICCP klasyfikacją można wyróżnić kilka form ich występowania. Są to formy sferyczne - porowate, na podstawie grubości ścianek określane jako cienkościenne (ścianki do $3 \mu \mathrm{m}$ ) - tenuisphere (fot. 1) i grubościenne (ścianki od $3 \mu \mathrm{m}$ ) - crassisphe$r e$ (fot. 2). Wielkość obserwowanych cenosfer zawiera się w przedziale od 20 do $300 \mu \mathrm{m}$. Pory główne, zwykle kilka, ulokowane są w centrum cenosfer natomiast pory mniejszych rozmiarów są bardziej liczne i występują w sąsiedztwie por głównych jak również w obrębie ścianek. Ponadto niespalona substancja organiczna tworzy ziarna o kształcie nieregularnym, porowate o rozmiarach od kilkunastu $\mu \mathrm{m}$ do ponad $1 \mathrm{~mm}$. Pory główne $\mathrm{w}$ tych cząstkach o wymiarach od około 20 do $200 \mu \mathrm{m}$ otoczone są ściankami o różnej grubości, w których często występują pory o mniejszych rozmiarach. W przypadku, gdy grubość ścianek jest poniżej $3 \mu \mathrm{m}$ ziarna klasyfikowane są jako tenuinetwork (fot. 3), natomiast gdy ścianki są grubsze - powyżej $3 \mu \mathrm{m}$ - tworzą formy określane jako crassinetwork (fot. 4). W badanych preparatach stwierdzono również ziarna o złożonej budowie, w których jedną część stanowi struktura porowata, a drugą masywna. W zależności od tego, która struktura jest dominująca ilościowo wyróżnia się typ mixed porous (fot. 5) w przypadku gdy dominująca jest struktura porowata i typ mixed dence (fot. 6) w przypadku gdy ilościowo przeważa struktura masywna. Struktura porowata (fot. 3,5) może wykazywać podobieństwo do plastra miodu (Misz 2002). W badanych próbkach występuje również substancja organiczna inertynitowa w formie fuzynitu wykazującego strukturę komórkową (fot. 9), niekiedy są to formy masywne (fot. 8) lub zwarte (fot. 7). Występują również cząstki organiczne zawierające domieszki mineralne - przeobrażonej substancji ilastej (fot. 12). Substancja organiczna w tych cząstkach jest zróżnicowana i występuje w formie detrytycznej, gdzie na detrytus składają się wymieszane fragmenty substancji organicznej pierwotnie sfuzynizowane i niesfuzynizowane. W cząstkach tych pory wykazują niewielkie rozmiary, a często jest ich brak i wówczas substancja organiczna wymieszana $\mathrm{z}$ mineralną występuje $\mathrm{w}$ formie masywnej. W przypadku, gdy ilość substancji mineralnej przekracza 50\%, cząstki te (fot. 10) klasyfikowane są jako mineralne (mineroid). W ilości dochodzącej do kilku procent substancja organiczna występuje w formie detrytycznej (fot. 11), gdzie wielkość pojedynczych ziaren nie przekracza $10 \mu \mathrm{m}$.

Dla struktur porowatych obliczono współczynnik porowatości jako iloraz wartości powierzchni zajmowanej przez pory do powierzchni substancji węglowej, w obrębie której występują pory. Wielkość ta jest największa dla struktur typu tenuisphere, tenuinetwork i osiąga wartości powyżej $80 \%$, maksymalnie $87 \%$ (fot. 1). Współczynnik porowatości dla struktur określanych jako crassisphere i crassinetwork osiąga wartości od powyżej 50\% do $79 \%$, co jest pomierzoną wartością maksymalną (fot. 4). Dla struktur typu fusinoid/solid 
porowatość wynosi od kilku procent (fot. 8) i może dochodzić do 80\%, w przypadku prezentowanym na fotografii 9 wynosi $68 \%$.

\section{Podsumowanie}

Substancja organiczna w badanych próbkach występuje w ilości 4,1-7,9\%. Cząstki organiczne wykazują duże zróżnicowanie zarówno pod względem wielkości jak i morfologii. Ich wielkość waha się w przedziale od kilku $\mu \mathrm{m}$ do około $1 \mathrm{~mm}$. Formy ich występowania można zaklasyfikować zgodnie z proponowaną klasyfikacją opracowaną przez ICCP - International Committee for Coal and Organic Petrology (Lester i in. 2010). Są to formy: sferyczne porowate cienkościenne i grubościenne, nieregularne ziarna porowate, których ścianki są o zmiennej grubości, substancja inertynitowa w formie fuzynitu wykazującego strukturę komórkową lub formy masywne bądź zwarte, cząstki organiczne zawierające domieszki mineralne i cząstki mineralne, gdy zawartość substancji organicznej jest poniżej $50 \%$. W proponowanej klasyfikacji nie uwzględniono cząstek detrytycznych, które zwykle licznie występują w popiołach lotnych ze spalania węgla i ilościowo dominują nad pozostałymi cząstkami. Taką pozycję umieścili w swojej klasyfikacji Alvarez i inni (1997), gdzie za cząstki detrytyczne uznane zostały fragmenty o powierzchni poniżej $500 \mu \mathrm{m}^{2}$.

Obliczona wielkość porowatości jest największa dla ziaren cienkościennych o kształcie nieregularnym oraz cenosfer i osiąga wartości powyżej $80 \%$, maksymalnie $87 \%$, co jest zgodne z proponowanymi wartościami w klasyfikacji ICCP. Współczynnik porowatości dla cząstek o podobnym kształcie ale grubościennych osiąga wartości od powyżej 50 do 79\%, co znacznie przekracza wartości zawarte w tej klasyfikacji. Dla struktur typu fusinoid/solid porowatość wynosi od kilku do $80 \%$ i w tym przypadku jest zgodna z wartościami proponowanymi przez ICCP.

Szczegółowe badania petrograficzne pozostałej po spaleniu substancji organicznej są interesującym uzupełnieniem do standardowo wykonywanych badań fizycznych, chemicznych i fazowych popiołów lotnych, w celu ich wykorzystania w różnych dziedzinach przemysłu.

Pracę wykonano w ramach badań statutowych AGH nr 11. 11. 140. 320.

\section{LITERATRURA}

Alvarez i in. 1997 - Alvarez, D., Angelez, G., Borrego, G. i Menendez, R. 1997. Unbiased methods for the morphological description of char structures. Fuel Vol. 76. No. 13, s. 1241-1248.

Bech, N.I. i Feuerborn, H.J. 2008. Utilization of coal ash in Europe. Int. Conf. Eurocoalash, Warsaw, Poland, 6-8 October 2008, s. 9-27.

Fenelonov i in. 2010 - Fenelonov, V.B., Melgunov, M.S. i Parmon, V.N. 2010. The Properties of cenospheres and the mechanism of their formation during high-temperature coal combustion at thermal power plans. KONA Powder and Particle Journal No. 28, s. 189-208. 
Fisher i in. 1976 - Fisher, G.L., Chang, D.P.Y. i Brummer, M. 1976. Fly ash collected from electrostatic precipitators: Microcrystalline structures and the mystery of thespheres. Science Vol. 192, s. 553-555.

Giergiczny, Z. 2013. Popiół lotny w składzie cementu i betonu. Gliwice: Wyd. Politechniki Śląskiej, 189 s.

Jun-Min i in. 2001 - Jun-Min, S., Qiang, Y. i Xu-Chang, X. 2001. Classification of Micro-Particles in Fly Ash. Dev. Chem. Eng. Mineral Process 9(3/4), s. 233-238.

Jonczy i in. 2012 - Jonczy, I., Nowak, J., Porszke, A. i Strzałkowska, E. 2012. Składniki fazowe wybranych mineralnych surowców odpadowych w obrazach mikroskopowych. Gliwice: Wyd. Politechniki Śląskiej, $200 \mathrm{~s}$.

Kurdowski, W. 2010. Chemia cementu i betonu. Stowarzyszenie Producentów Cementu, Wyd. Naukowe PWN, Kraków, Warszawa, $728 \mathrm{~s}$.

Kutchko, B.G. i Kim, A.G. 2006. Fly ash characterization by SEM-EDS. Fuel 85, s. 2537-2544.

Lester $\mathrm{i}$ in. 2010 - Lester, E., Alvarez, D., Borrego, A.G., Valentim, B., Flores, D., Clift, D.A., Rosenberg, P., Kwiecinska, B., Barranco, R.,. Petersen, H.I, Mastalerz, M., Milenkova, K.S., Panaitescu, C., Marques, M.M., Thompson, A., Watts, D., Hanson, S., Predeanu, G., Misz, M. i Tao, Wu. 2010. The procedure used to develop a coal char classification - Commission III CombustionWorking Group of the International Committee for Coal and Organic Petrology. International Journal of Coal Geology 81, s. 333-342.

Mazurkiewicz i in. 1997 - Mazurkiewicz, M., Piotrowski, Z. i Tajduś, T. 1997. Lokowanie odpadów w kopalniach podziemnych. Kraków: Biblioteka Szkoły Eksploatacji Podziemnej, 124 s.

Misz, M. 2002. Comparison of chars in slag and fly ash as formed in pf boilers from Będzin Power Station (Poland) Fuel Vol. 81, s. 1351-1358.

Shackelford, J.F. i Doremus, H. red. 2008. Ceramic and Glass Materials: Structure, Properties and Processing. Springer, $209 \mathrm{~s}$.

Sokol i in. 2002 - Sokol, E.V., Kalugin, V.M., Nigmatulina, E.N., Volkova, N.I., Frankel, A.E. i Maksimova, N.V. 2002. Ferrospheres from fly ashes of Chelyabinsk coal: chemical composition, morphology and formation conditions. Fuel 81, s. 867-876.

Ramsden, A.R. i Shibaoka, M. 1982. Characterization and analysis of individual fly ash particles from coal-fired power stations by a combination of optical microscopy: Electron microscopy and quantitative electron microprobe analysis. Atmos. Environ Vol. 16, No. 9, s. 2191-2206.

Ratajczak i in. 1999 - Ratajczak, T., Gaweł, A., Górniak, K., Muszyński, M., Szydłak, T. i Wyszomirski, P. 1999. Charakterystyka popiołów lotnych ze spalania niektórych węgli kamiennych i brunatnych. Polskie Towarzystwo Mineralogiczne - Prace specjalne, s. 9-34.

Tadeusiewicz, R. i Korhoroda, P. 1997. Komputerowa analiza i przetwarzanie obrazów. Wyd. Fundacji Postępu Telekomunikacji: Kraków, 272 s.

Uliasz-Bocheńczyk, A. 2008. Możliwości zastosowania popiołów lotnych ze spalania węgla kamiennego w kotłach wodnych do sekwestracji $\mathrm{CO}_{2}$ na drodze mineralnej karbonatyzacji. Rocznik Ochrony Środowiska t. 10, s. $567-574$.

\title{
CZĄSTKI WĘGLOWE W POPIOLACH LOTNYCH ZE SPALANIA WĘGLA Z POLSKICH ZLÓŻ
}

\author{
Słowa kluczowe
}

węgiel, petrografia, popioły lotne

\section{Streszczenie}

Niespalona substancja organiczna w popiołach lotnych występuje najczęściej w formie ziaren masywnych lub porowatych, niekiedy przyjmujących postać cenosfer. W badanych popiołach lotnych ze spalania węgli brunatnych i kamiennych pochodzących z elektrowni cieplnych stwierdzono wy- 
stępowanie mikrocząstek należących do następujących grup: glinokrzemiany (kwarc, mulit), tlenki żelaza, węglany oraz niespalona substancja organiczna.

Substancja organiczna w badanych próbkach występuje w ilości 3,6-9,5\%. Cząstki węglowe wykazują duże zróżnicowanie zarówno pod względem wielkości jak i morfologii. Ich wielkość waha się w przedziale od kilku $\mu \mathrm{m}$ do około $1 \mathrm{~mm}$. Można wyróżnić kilka form ich występowania. Są to formy sferyczne porowate cienkościenne i grubościenne. Ponadto niespalona substancja organiczna tworzy nieregularne ziarna porowate, których ścianki są o zmiennej grubości. W badanych próbkach występuje również substancja organiczna inertynitowa w formie fuzynitu wykazującego strukturę komórkową lub niekiedy są to formy masywne lub zwarte. Częstą formą występowania substancji organicznej w badanych popiołach lotnych są cząstki detrytyczne o wymiarach poniżej $10 \mu \mathrm{m}$. Występują również cząstki węglowe zawierające domieszki mineralne. W przypadku, gdy ilość substancji mineralnej przekracza 50\%, cząstki te klasyfikowane są jako mineralne.

W celach dokumentacyjnych oraz do określenia porowatości wykonano zdjęcia mikroskopowe obserwowanych cząstek węglowych. Porowatość określono stosując komputerową analizę obrazu poprzez binaryzację i progowanie odcieni szarości. Dla struktur porowatych obliczono współczynnik porowatości jako iloraz wartości powierzchni zajmowanej przez pory do powierzchni substancji węglowej, w obrębie której występują pory. Wielkość ta jest największa dla ziaren cienkościennych o kształcie nieregularnym oraz cenosfer i osiąga wartości powyżej $80 \%$, maksymalnie $87 \%$. Współczynnik porowatości dla cząstek o podobnym kształcie ale grubościennych osiąga wartości od powyżej 50 do 79\%, co jest pomierzoną wartością maksymalną. Dla struktur typu fusinoid/solid porowatość wynosi od kilku do $80 \%$.

\section{COAL PARTICLES IN THE FLY ASHES FROM POLISH COAL COMBUSTION}

\section{Keywords}

coal, petrography, fly ash

Abstract

Unburned organic matter in the fly ash occurs most commonly in the form of solid or porous grains. It has been shown that tested fly ash resulting from the combustion of lignite and hard coal from pulverized boilers contained microparticles belonging to the following groups: aluminosilicates (quartz, mullite), iron oxides, carbonates, and unburned organic matter.

The organic matter content in the tested samples is in the range of 3.6-9.5\%. Coal particles show a large variation in terms of size and morphology. Their size ranges from a few micrometers to about $1 \mathrm{~mm}$. Several forms of their occurrence can be distinguished. These include: porous, thin and thick-walled spherical forms. In addition, unburned carbonaceous substance creates irregular porous grains with walls of variable thickness. What is more, the tested samples contain macerals from the inertinite group in the form of fusinite showing cellular structure; sometimes these include massive or dense forms. The organic matter in the tested fly ash usually occurs in the form of detrital particles with dimensions below 10 micrometers. There are also coal particles con- 
taining mineral admixtures. If the mineral matter content exceeds $50 \%$, the particles are classified as minerals.

The microscopic pictures of the tested coal particles were made for documentation purposes and to determine the porosity. The porosity was determined with the use of computerized image analysis using binarization and thresholding a grayscale. The void ratio for porous structures was calculated as the ratio of the area occupied by pores to the surface of the carbonaceous material containing pores. This ratio is the largest for the thin-walled grains of irregular shape and cenospheres, reaching values above $80 \%$, maximally up to $87 \%$. The porosity ratio for particles of similar shape but thick-walled ranges from above $50 \%$ to $79 \%$ which is the maximum value measured. In the case of fusinoid/solid structures, the porosity ranges from several to $80 \%$. 